\title{
Therapy of lupus nephritis: lessons learned from clinical research and daily care of patients
}

\author{
Frédéric A Houssiau*
}

\begin{abstract}
Despite numerous randomized clinical trials over the last three decades for identifying the optimal treatment option for lupus nephritis, renal involvement still significantly impacts the survival and quality of life of patients with lupus and the search for the ideal immunosuppressive regimen is far from complete. The purpose of this review is to summarize the major recent achievements in the field. More specifically, the following topics will be discussed: intravenous cyclophosphamide versus mycophenolate mofetil (MMF) for induction; azathioprine versus MMF for maintenance; targeted therapies. The review will address clues for optimal global care, such as the need for complete initial evaluation, the importance of patient education, the unmasking of non-compliance to therapy, the reason for an early treatment switch in non-responding patients, the need for prolonged immunosuppression, optimal renal protection, and prevention of cardiovascular disease and other comorbidities.
\end{abstract}

Although short- and medium-term prognosis of lupus nephritis (LN) has improved dramatically over the last decades, long-term outcome remains unsatisfactory not only because of progression toward end-stage renal disease (ESRD) in a significant subset of patients followed up over decades but also because of disease- or treatmentrelated comorbidities that clearly impact quality of life and survival. Thus, we are pleased to claim that $92 \%$ of patients randomly assigned in the Euro-Lupus Nephritis Trial (ELNT) are still alive at 10 years [1]. But what does a 10-year survival rate for a group of patients who were 30 years old at baseline really mean, a fortiori, for teenage girls?

*Correspondence: frederic.houssiau@uclouvain.be

Rheumatology Department, Cliniques Universitaires Saint-Luc, Université catholique de Louvain, Avenue Hippocrate, 10, B-1200 Bruxelles, Belgium
After 20 years of personal involvement in clinical research in the field of $\mathrm{LN}$, the author of this review became convinced that optimal care of patients with LN relies at least as much upon excellent daily care given in specialized centers aimed at controlling all aspects of such a complex disease as upon the choice between one immunosuppressant or another. In other words, currently available drugs, such as cyclophosphamide (CY), mycophenolate mofetil (MMF), or azathioprine (AZA), used in an appropriate way are by and large equivalent at inducing (or not!) and maintaining (or not!) a clinical response. In $\mathrm{LN}$, as in many other chronic diseases, until a wonder drug is available, most of the differences in outcome may well be related to the quality of care. So this review will start by emphasizing the clues for optimal care in LN, which really makes the difference, before summarizing some recent achievements - and failures! - during the last decade and some hopes for the future. Since several excellent and exhaustive reviews have been published recently [2-4], this paper strives to be well balanced but not to be the final word on the subject.

\section{Clues for optimal care in lupus nephritis Complete initial evaluation}

Patients with LN should undergo complete evaluation before treatment is started. This should include (a) full assessment of disease activity by using validated scores such as the Systemic Lupus Erythematosus Disease Activity Index (SLEDAI), the European Consensus Lupus Activity Measurement (ECLAM) index, and the British Isles Lupus Assessment Group (BILAG) index; (b) complete serological testing, including antiphospholipid (APL) antibody status; (c) at least one 24-hour urine collection for proteinuria measurement (and not only urinary spot protein/creatinine ratio); and (d) a renal biopsy for direct immunofluorescence studies (a 'full house' pattern is very indicative of LN), for classification according to the International Society of Nephrology/Renal Pathology Society (ISN/RPS) grading system, for exclusion of APL-associated thrombotic microangiopathy, and for assessment of activity and chronicity indices. In this respect, the presence of hyperactive lesions, such as crescents or 
glomerular necrosis, should guide therapy at the bedside at least as much as the ISN/RPS class itself.

\section{Education and obsessional follow-up}

At diagnosis, physicians, dedicated nurse practitioners, and patient associations should provide adequate educational material that replaces inaccurate and mostly frightening uncontrolled websites and forums that create misconceptions. Follow-up must be obssessional, follow a standardized scheme, and directly involve patients (for example, by allowing them direct access to their own medical chart, as already practiced in some Scandinavian countries and as tested in our own lupus clinic).

\section{Unmasking non-compliance to therapy}

Non-adherence to pharmacological therapy is one of the major reasons for treatment failure. It should be discussed with the patient from the very first visit and always suspected in 'refractory' cases. Measurements of whole-blood hydroxychloroquine titers may help in detecting poor adherence, based on the long elimination half-life of the drug, thereby bypassing the so-called 'white coat compliance' (in which the patient takes a few pills before the visit!). Using this approach as an objective marker of poor adherence to therapy, a recent study could demonstrate that non-compliant patients with lupus experienced more lupus flares [5].

\section{Less glucocorticoid}

No drug has improved survival of patients with LN as dramatically as glucocorticoids (GCs). However, no drug has been responsible for as many side effects! In randomized trials, many of the severe infections attributed to one immunosuppressive regimen or another may well be due to GCs, their common denominator. Intriguingly, the dose of GCs needed to control LN is an understudied topic. Recent trials have successfully used a starting oral prednisolone daily dose of $0.5 \mathrm{mg} / \mathrm{kg}$ (associated with a few intravenous (IV) methylprednisolone (MP) pulses) instead of the 'classical' $1 \mathrm{mg} / \mathrm{kg}$ oral daily dose [6,7]. That oral GC therapy can be completely left out of an induction immunosuppressive regimen is far from proven but is suggested by a recent uncontrolled study showing that 13 of 46 patients (28\%) with LN went into complete renal remission at 6 months after treatment with $2 \mathrm{~g}$ of rituximab ( $1 \mathrm{~g}$ given intravenously twice 2 weeks apart) combined with IV MP (500 mg given twice 2 weeks apart) and followed by MMF with no oral GCs [8].

\section{Individualized therapy}

As researchers, we rightly consider that results of randomized trials should be translated as such at the bedside. But as clinicians, we know that many variables other than evidence-based medicine will guide therapy.
Ethnicity, age, doubts about compliance, severity of the clinical presentation, renal pathology findings, and comorbidities will obviously be taken into account. More and more, patient-oriented issues such as pregnancy plans or even fear of certain side effects will contribute to the decision.

\section{Early treatment switch}

We would hope that all patients with LN would respond to the same first-line immunosuppressive therapy. Again, as clinicians, we know that this assumption is not valid and we are still very bad at predicting who is going to respond to which drug, in particular because we largely ignore pharmacogenomic issues and the pathogenic pathways at work in a given patient. In other words, we proceed by a 'trial and error' approach. One way to overcome this shortcoming is to evaluate the early response to therapy and then switch to another treatment in case of an unsatisfactory response. We indeed demonstrated, in a long-term prospective trial, that an early response to immunosuppressive therapy at 6 months was the best predictor for a good long-term renal outcome in LN [9]. Thus, patients with a good long-term renal outcome, defined by a serum creatinine value of not more than $1.4 \mathrm{mg} / \mathrm{dL}$ after a follow-up of more than 5 years, experienced a prompt and dramatic drop in proteinuria after 3 and 6 months of therapy, and this was not the case in patients who later developed renal impairment. The positive predictive value of a $75 \%$ decrease in proteinuria at 6 months for good long-term renal outcome was $90 \%$.

\section{Prolonged maintenance immunosuppression}

Although we lack prospective trials specifically aimed at comparing different lengths of maintenance immunosuppressive regimes, the very high renal relapse rate $(35 \%$ in most long-term series) favors prolonged immunosuppression [10]. In a small but interesting withdrawal study performed in patients with LN, an inverse correlation between the length of treatment/remission before withdrawal and the risk of relapse was found [11]. Interestingly, in Europe, the current practice (as reflected by the 10-year follow-up data from the ELNT) is to keep patients long-term on AZA (or MMF) and on low-dose GCs. Thus, after 10 years, $73 \%$ and $56 \%$ of patients randomly assigned in the trial were still on low-dose prednisolone (mean daily dose of $5.5 \mathrm{mg}$ ) and on another immunosuppressant, respectively [1]. The possibility that the excellent long-term outcome in these patients (only 7\% ESRD at 10 years) is linked to prolonged immunosuppression is far from proven yet is not too far fetched.

\section{Optimal renal protection}

In LN, as in other chronic renal diseases (see guidelines of the Kidney Disease Outcomes Quality Initiative and of 
Kidney Disease: Improving Global Outcomes), blood pressure must be tightly controlled and maximal systolic/ diastolic values should not exceed 120/80 mm Hg. Antiprotenuric therapy should be prescribed in all patients with $\mathrm{LN}$ by combining, if needed, angiotensin-converting enzyme inhibitor (ACEI), angiotensin receptor blocker (ARB), and loop diuretics.

\section{Prevention of cardiovascular disease}

Pivotal data by the Toronto group first demonstrated a bimodal mortality pattern in patients with lupus by showing an early peak related to lupus itself and its therapy and a second peak due to cardiovascular disease [12]. This observation was confirmed in patients with lupus by the demonstration of accelerated atheroma as assessed by carotid Doppler studies (plaques and intimamedia thickness) [13] and by coronary computerized tomography scan studies (calcifications) [14]. In this respect, control of all cardiovascular risk factors, such as smoking avoidance, weight control, exercise, and cholesterol levels, is of the utmost importance. As for diabetes mellitus, we set the low-density lipoprotein cholesterol cutoff value for treatment with a cholesterol-lowering drug as low as $115 \mathrm{mg} / \mathrm{dL}$.

\section{Prevention of other comorbidities}

Several studies have demonstrated that many patients with lupus suffer from GC-induced osteoporosis, which should always be prevented by calcium salts and vitamin $\mathrm{D}_{3}$ supplements and, in selected cases, by bisphosphonates [15]. All patients with lupus should be immunized against Streptococcus pneumoniae given the incidence and severity of the infections caused by this pathogen [16]. The higher prevalence of uterine cervix carcinoma and human papillomavirus infection in patients with lupus in comparison with a control population [17] strongly argues in favor of early immunization in teenage patients with lupus.

\section{Achievements and failures over the last decade}

Mayo Clinic and National Institutes of Health (NIH) investigators deserve the credit for running the first controlled trials in LN and for stressing the need for long-term follow-up to unmask differences between treatment arms. For decades, we have been prescribing the so-called 'NIH regimen' consisting of monthly (for 6 months) and then quarterly (for up to 1 year after complete remission) high-dose ( 0.75 to $\left.1.5 \mathrm{~g} / \mathrm{m}^{2}\right)$ intermittent IV CY pulses, combined mostly with IV MP pulses [1820]. Although this regimen was shown to be superior to GCs at preserving renal function in the long run, the associated high incidence of premature gonadal failure made it unpopular among young female patients with LN and thereby generated alternative proposals, including the use of lower doses of IV CY (the Euro-Lupus regimen) or the use of MMF.

\section{The Euro-Lupus regimen: 20 years later}

Low-dose IV CY was introduced by Graham Hughes at St. Thomas' Hospital in London in order to minimize the side effects of the drug. A sequential approach consisting of prescribing a potentially toxic drug (IV CY) for a short period of time before switching to a more patient-friendly drug, namely AZA, for a long period of chronic immunosuppression was suggested [21]. The concept was further tested in a controlled trial, the ELNT, taking advantage of a European network of physicians who had trained together in Hughes's lupus unit.

Briefly, we compared an NIH-like IV CY regimen (monthly pulses for 6 months and two additional quarterly pulses) and a low-dose IV CY regimen (six fortnightly pulses of a fixed dose of $500 \mathrm{mg}$ ), both of which were followed by AZA (started at week 12 in the low-dose group and at week 44 in the high-dose group) [6]. All patients received three IV MP pulses of $750 \mathrm{mg}$ and a moderate dose of oral prednisolone (starting mostly at $0.5 \mathrm{mg} / \mathrm{kg}$ per day) with a stringent tapering regimen. To summarize, after 10 years of follow-up, the low-dose regimen achieved results comparable to those of the $\mathrm{NIH}$-like protocol, and there was a very low rate of ESRD (7\%) [1]. Whether this conclusion, based on a European trial performed in a population composed mainly of Caucasians, can be extrapolated to other ethnic groups is currently unknown. It has been said that patients included in the ELNT did not suffer from severe renal disease. While this is true based on the percentage of patients presenting with nephrotic syndrome $(28 \%)$ or renal impairment $(22 \%)$ or both, it should be stressed that all suffered from biopsy-proven proliferative LN and that $47 \%$ of them had partial circumferential crescents on central pathology review. In this respect, the possibility that patients were captured in very early clinical stages of LN is not too far fetched. Most patients were indeed followed in rheumatology-based lupus clinics, and early kidney involvement was therefore promptly detected by very regular dipstick examinations. Such a recruitment obviously differs from that of a nephrology clinic, where patients with LN present mostly with acute renal failure, implying that the underlying process is already at work for weeks or months before it is detected. In this subset of patients, the lack of significant extra-renal disease activity may delay the diagnosis of systemic lupus erythematosus.

Although some caveats against an indiscriminate use of the low-dose IV CY regimen can be raised, the many advantages of this regimen must be emphasized: no need for prolonged in-patient stay (500 $\mathrm{mg}$ of IV CY can be administered as a 30-minute drip infusion in a day clinic), 
no need for hyperhydration, no need for mesna, no need to monitor white blood cell count, optimal compliance (IV route), and - last but not least - virtually no risk of premature gonadal failure.

\section{Mycophenolate mofetil: the challenger saga}

No other drug has generated as much hope in LN as MMF over the last decade. Yet more than 10 years after the first randomized controlled trial comparing oral $\mathrm{CY}$ and MMF [22], the jury is still out. The drug was introduced as an immunosuppressant in transplant medicine, in which it was shown to be superior to AZA at preventing graft rejection [23], although not all transplant teams share this view [24]. Logically, MMF has been tested in $\mathrm{LN}$ as an induction immunosuppressant and as a maintenance drug.

In a randomized LN trial (in which more than half of the participants were African-American) in the US, MMF was found to be superior to NIH IV CY at inducing complete remission of renal signs at 6 months $(22.5 \%$ in the MMF group versus $5.8 \%$ in the IV CY arm) [25]. However, in a subsequent multiethnic trial (the Aspreva Lupus Management Study, or ALMS), the two immunosuppressants were found to be equivalent at inducing a renal response at 6 months $(56.2 \%$ in the MMF group versus $53.0 \%$ in the IV CY arm), and MMF showed an advantage over IV CY in non-Caucasian/non-Asian patients [26]. To summarize, MMF can be considered to be at least equivalent to $\mathrm{CY}$ at inducing an early renal response, although we still lack long-term data (that is, 10-year follow-up) on patients induced with MMF. As mentioned above, the decision to start MMF or $\mathrm{CY}$ at the bedside will be influenced by many variables. Thus, if one anticipates non-observance to therapy, low-dose IV CY may be the ideal choice. Conversely, in a 38-year-old African-American woman with pregnancy plans, it may be wiser to prescribe MMF. The relatively low rate of renal response and, a fortiori, the very low rate of renal remission at 6 months (regardless of the initial therapy and despite the use of high-dose GCs) clearly illustrate the need for induction regimes that are more efficacious. On the other hand, the availability of at least two drugs, besides GCs, to initiate immunosuppression leaves open the possibility of switching patients not responding to one drug to the other, although this has not been supported by data so far.

MMF was also proven effective for maintenance immunosuppression in LN. In a first trial, Contreras and colleagues [27] compared quarterly high-dose IV CY pulses (NIH), AZA, and MMF for maintenance therapy after induction with monthly IV CY pulses. Mortality (in particular, mortality due to infections) was significantly higher in the IV CY group in comparison with the two other groups, a result that largely contributed to a ban on quarterly IV CY pulses. Two other randomized trials the maintenance phase of the ALMS [28] and the MAINTAIN Nephritis Trial [7] - have compared AZA and MMF for maintenance immunosuppression.

Patients who were randomly assigned in the ALMS and who had responded to MMF or IV CY at 6 months ( $\pm 50 \%$ of the original cohort) were randomly assigned again to receive AZA or MMF for an additional period of 3 years. The primary outcome measure for the maintenance phase was time to treatment failure, a composite endpoint that consisted of renal flare, sustained doubling of serum creatinine, initiation of rescue therapy for LN, ESRD, and death. According to Kaplan-Meier analysis, time to treatment failure was statistically shorter for AZA patients in comparison with MMF patients. Superiority of MMF over AZA was demonstrated not only for patients who had achieved a response at 6 months with MMF (36\% and 21\% failure rates in the AZA and MMF maintenance groups, respectively) but also for patients induced with IV CY (28\% and $11 \%$, respectively). Of note, the lowest failure rate was observed in patients who had been induced with IV CY and maintained with MMF. Side effects were comparable [28].

In the MAINTAIN Nephritis Trial [7], which was performed in a Caucasian European population, all patients received the same induction regimen, namely GCs (IV MP and oral) and six fortnightly pulses of IV CY (according to the Euro-Lupus regimen). At month 3, irrespectively of the magnitude of their renal response, patients were switched to AZA or MMF on the basis of the random assignment performed at baseline. Time to renal flare (the primary endpoint of the trial) did not differ after a 5 -year follow-up period: the renal flare rates were $19 \%$ and $25 \%$ for MMF and AZA patients, respectively, and this difference was not statistically significant. Side effects, except for transient cytopenias (which were more frequent in the AZA group), did not differ between the two groups. Repeat renal biopsies performed 2 years after random assignment in a representative set of patients failed to reveal an advantage of one drug over the other in terms of activity/chronicity indices [29].

The design and patient population of the two MMF/ AZA maintenance LN trials are so different that one should avoid comparing them head-to-head. Rather, we would suggest interpreting the results in a positive way since at least two drugs are available for long-term use in patients with LN and have a reasonable efficacy and toxicity profile, thereby - again - suggesting that patients failing on one drug could be rescued by the other.

\section{Targeted therapies: sparks twinkling in the night or falling stars?}

Several biologics have been, are, or will be evaluated in LN. Results of randomized trials are available for 
rituximab (RTX) (anti-CD20 mAb), ocrelizumab (OCR) (humanized anti-CD20 mAb), and abatacept (CTLA4-Ig). Sadly, these results were not conclusive.

The LUNAR (Lupus Nephritis Assessment with Rituximab) trial was a phase III, randomized, doubleblinded, placebo-controlled, multicenter study of 144 class III or IV patients with LN [30]. All patients received GCs $(2 \mathrm{~g}$ of IV MP followed by $0.75 \mathrm{mg} / \mathrm{kg}$ per day of prednisolone) and MMF (up to $3 \mathrm{~g} /$ day) as background therapy. RTX (two infusions of $1 \mathrm{~g}, 15$ days apart with retreatment 6 months later) or placebo was given as add-on treatment. The primary outcome (that is, the proportion of patients achieving complete or partial renal response at week 52) was met by $57 \%$ and $46 \%$ of the patients randomly assigned in the RTX and placebo groups, respectively. This difference was not statistically significant. A trend in favor of RTX was noted in African-Americans (70\% versus $45 \%$; $P=0.20$ ).

The BELONG trial was aimed at testing the efficacy and safety of OCR (400 or 1,000 mg given on days 1 and 15 and weeks 16 and 32) in patients with active ISN/RPS class III or IV LN treated with standard of care (SOC) consisting of GCs ( 0.5 to $0.75 \mathrm{mg} / \mathrm{kg}$ per day; with taper to not more than $10 \mathrm{mg} /$ day over the course of 10 weeks) and either MMF (up to $3 \mathrm{~g} /$ day; $63 \%$ of the patients) or the Euro-Lupus regimen (IV CY $500 \mathrm{mg}$ six times every 2 weeks, followed by AZA $2 \mathrm{mg} / \mathrm{kg}$ per day; $37 \%$ of the patients), as selected by investigators [31]. The study was terminated early in September 2009 (after complete enrollment) because an interim analysis by the Data and Safety Monitoring Board revealed safety concerns. Thus, serious infections (that is, requiring IV antibiotics) were two times more common in the $400 \mathrm{mg}$ OCR group (but, surprisingly, not in the $1,000 \mathrm{mg}$ OCR group) in comparison with placebo. Intriguingly, this was the case only in the subgroup of patients given MMF as SOC background therapy (not on Euro-Lupus background). In a modified intent-to-treat population, $63.3 \%$ of the OCR patients achieved complete or partial renal response in comparison with $51.4 \%$ of the placebo patients $(P=0.07)$. Interestingly, the difference was more pronounced, in favor of OCR, in patients given the Euro-Lupus regimen as SOC background treatment (59.4\% versus $42.9 \%$ ).

The negativity of these two B-cell blockade LN trials, together with the negative results of the EXPLORER (Exploratory Phase II/III Systemic Lupus Erythematosus Evaluation of Rituximab) trial performed in patients with non-renal lupus [32], contrasts with the clinical practice of experienced physicians who have been successfully using RTX in LN cases who had failed on conventional therapy [33], thereby raising concerns about the design of the two RTX LN studies. Did concomitant therapy (with high doses of GCs and other immunosuppressants) mask the effects of RTX? Were the trials too short-term to unmask the benefits of RTX? Were the doses of RTX appropriate? Should RTX be prescribed only in a subset of early refractory LN cases that do not respond to SOC after 3 to 6 months? These are some of the many questions that should be addressed before RTX can be considered a falling star! In this respect, the recent positive results of EMBLEM [34], a short-term phase II epratuzumab (anti-CD22) trial performed in patients with lupus without severe renal/central nervous system involvement, further stress the potential value of a B-cell blockade approach in lupus.

Two randomized trials were designed in order to test the efficacy of abatacept as add-on induction therapy for LN. The molecule, also called CTLA4Ig, is a selective T-cell co-stimulation modulator that binds to B7 (expressed on antigen-presenting cells) and thereby blocks its interaction with CD28, expressed on T cells, preventing T-cell activation. An industry-sponsored trial testing abatacept on a GC and MMF background was recently reported to be inconclusive [35]. We now eagerly await the results of ACCESS (Abatacept and Cyclophosphamide Combination: Efficacy and Safety Study), a study that was sponsored by the Immune Tolerance Network and the National Institute for Allergy and Infectious Diseases and that was aimed at comparing abatacept and placebo on a Euro-Lupus regimen background.

Other biologics, such as anti-BLyS belimumab, antiCD22 epratuzumab, anti-interleukin 6 , or anti-type I interferons, will most likely be tested in LN. The very recent US Food and Drug Administration (FDA) approval of belimumab for the treatment of moderately severe lupus, after the success of two phase III pivotal trials performed in patients with non-renal lupus [36,37], will likely trigger a proper $\mathrm{LN}$ trial with the drug.

\section{Treatment of membranous lupus nephritis}

Membranous lupus glomerulonephritis (ISN/RPS class V LN) is characterized by subepithelial immune deposits. It is usually associated with proliferative disease, namely ISN/RPS class III (focal) or IV (diffuse) LN. In this case, most physicians consider that the presence of proliferative lesions guides therapy. However, some patients suffer from isolated ISN/RPS class V membranous LN either as the initial manifestation of renal involvement or later in their evolution. Thus, patients treated for proliferative disease sometimes switch to membranous LN unmasked by a control kidney biopsy performed because of persisting proteinuria despite immunosuppression.

Treatment of pure membranous LN probably does not differ from that of idiopathic membranous nephropathy. Based on the nephrology experience, a distinction must be made between nephrotic and subnephrotic patients. Thus, in subnephrotic patients, a 'watchful waiting' approach with optimal blockade of the angiotensin renin 
Table 1. Standard immunosuppressive drugs for induction and maintenance therapy of ISN/RPS class III/IV/V lupus nephritis

\begin{tabular}{|c|c|c|c|c|}
\hline Drug & Route & Dose & Induction & Maintenance \\
\hline \multirow[t]{4}{*}{ Glucocorticoids } & \multirow[t]{2}{*}{ Oral } & 0.5-1.0 mg/kg per day & Required & Advised \\
\hline & & Prefer 0.5 mg/kg per day & Combined with another IS & Low-dose (5-7.5 mg/day) \\
\hline & \multirow[t]{2}{*}{ IV } & \multirow[t]{2}{*}{ 500-1,000 mg MP } & Advised & Optional (every month to every 3 months) \\
\hline & & & 3 consecutive days & Consider in non-compliant patients \\
\hline \multirow[t]{6}{*}{ Cyclophosphamide } & Oral & $2 \mathrm{mg} / \mathrm{kg}$ per day & Only for highly selected severe cases & No \\
\hline & \multirow[t]{3}{*}{ IV NIH } & $500-1,000 \mathrm{mg} / \mathrm{m}^{2}$ & \multirow[t]{3}{*}{ Reasonable first choice } & \multirow[t]{3}{*}{ No } \\
\hline & & $\begin{array}{l}\text { Six monthly pulses dose adjusted } \\
\text { (WBC count nadir) }\end{array}$ & & \\
\hline & & Mesna advised & & \\
\hline & \multirow[t]{2}{*}{ IVEL } & $500 \mathrm{mg}$ fixed dose & \multirow[t]{2}{*}{ Reasonable first choice } & \multirow[t]{2}{*}{ NA } \\
\hline & & Six fortnightly pulses & & \\
\hline \multirow[t]{2}{*}{ Mycophenolate mofetil } & \multirow[t]{2}{*}{ Oral } & $1-3 \mathrm{~g} /$ day & Reasonable first choice & \multirow[t]{2}{*}{ Reasonable first choice } \\
\hline & & Target 2-3 g/day & $\begin{array}{l}\text { Preferred for non-Caucasians, } \\
\text { non-Asians }\end{array}$ & \\
\hline \multirow[t]{2}{*}{ Azathioprine } & \multirow[t]{2}{*}{ Oral } & 1.0-2.5 mg/kg per day & \multirow[t]{2}{*}{ Not first choice } & \multirow[t]{2}{*}{ Reasonable first choice } \\
\hline & & Target $2.0-2.5 \mathrm{mg} / \mathrm{kg}$ per day & & \\
\hline \multirow[t]{3}{*}{ Calcineurin inhibitors } & \multirow[t]{3}{*}{ Oral } & Cyclosporine: $2.5-3.0 \mathrm{mg} / \mathrm{kg}$ & \multirow[t]{3}{*}{ Not first choice } & Selected cases \\
\hline & & per day & & \multirow[t]{2}{*}{ Pure membranous lupus nephritis } \\
\hline & & Tacrolimus: 0.05 mg/kg per day & & \\
\hline \multirow[t]{2}{*}{ Plasma exchanges } & \multirow[t]{2}{*}{ NA } & 2-4 L/session & \multirow[t]{2}{*}{ Selected cases } & \multirow[t]{2}{*}{ No } \\
\hline & & Twice weekly, then weekly & & \\
\hline
\end{tabular}

EL, Euro-Lupus; IS, immunosuppressant; ISN/RPS, International Society of Nephrology/Renal Pathology Society; IV, intravenous; MP, methylprednisolone; NA, not applicable; NIH, National Institutes of Health; WBC, white blood cell.

aldosterone system is usually appropriate. In patients with nephrotic range proteinuria, immunosuppressants are usually added by combining GCs and one of the following drugs: CY, MMF, AZA, or calcineurin inhibitors. In a controlled trial performed at the NIH, 42 patients with pure membranous LN received (a) cyclosporine and alternate-day GCs, (b) alternate-month IV CY for six doses and alternate-day GCs, or (c) alternateday GCs alone. Regimes (a) and (b) were both found to be superior to (c) at 1 year, but, interestingly, while the effect was prompter with calcineurin inhibitors, relapses were more frequent than in the CY group [38]. A subset analysis performed in the 84 pure membranous LN cases randomly assigned in two large recent randomized LN trials comparing MMF and IV CY $[25,26]$ revealed that the two drugs were equally effective at 24 weeks [39].

\section{Conclusions}

Major progress has been achieved in the field of LN over the last decade. Table 1 tentatively summarizes the respective indications of the most commonly used immunosuppressants. We now use drugs in a much more patient-friendly way, thereby minimizing side effects. MMF is now clearly on board. We have at least two drugs for induction (MMF and IV CY) and maintenance (MMF and AZA) immunosuppression in LN. Together with ever increased standards for optimal global care, this has contributed to lower ESRD rates to figures never anticipated before. Recently, a new drug, anti-BLyS belimumab, became the first drug to be approved by the FDA for the treatment of LN since cortisone and hydroxychloroquine were labeled for lupus 52 years ago. These exciting times, however, should not disguise the fact that LN still impacts the survival of patients with lupus, that no cure can be offered at present, and that further research breakthroughs are still awaited.

\section{Abbreviations}

ALMS, Aspreva Lupus Management Study; APL, antiphospholipid; AZA, azathioprine; BLyS, B lymphocyte stimulator; CY, cyclophosphamide; ELNT, Euro-Lupus Nephritis Trial; ESRD, end-stage renal disease; FDA, US Food and Drug Administration; GC, glucocorticoid; ISN/RPS, International Society of Nephrology/Renal Pathology Society; IV, intravenous; LN, lupus nephritis; mAb, monoclonal antibody; MMF, mycophenolate mofetil; MP, methylprednisolone; $\mathrm{NIH}$, National Institutes of Health; OCR, ocrelizumab; RTX, rituximab; SOC, standard of care. 


\section{Competing interests}

The author declares that he has no competing interests.

\section{Acknowledgments}

The author is most grateful to patients and physicians who participated in the Euro-Lupus Nephritis Trial and to the MAINTAIN Nephritis Trial.

Published: 31 January 2012

\section{References}

1. Houssiau FA, Vasconcelos C, D'Cruz D, Sebastiani GD, de Ramon Garrido E, Danieli MG, Abramovicz D, Blockmans D, Cauli A, Direskeneli H, Galeazzi M, Gül A, Levy Y, Petera P, Popovic R, Petrovic R, Sinico RA, Cattaneo R, Font J, Depresseux G, Cosyns JP, Cervera R: The 10-year follow-up data of the EuroLupus Nephritis Trial comparing low-dose and high-dose intravenous cyclophosphamide. Ann Rheum Dis 2010, 69:61-64.

2. Ponticelli C, Glassock RJ, Moroni G: Induction and maintenance therapy in proliferative lupus nephritis. J Nephrol 2010, 23:9-16.

3. Bomback AS, Appel GB: Updates on the treatment of lupus nephritis. J Am Soc Nephrol 2010, 21:2028-2035.

4. Lightstone L: Lupus nephritis: where are we now? Curr Opin Rheumatol 2010, 22:252-256.

5. Costedoat-Chalumeau N, Amoura Z, Hulot JS, Aymard G, Leroux G, Marra D, Lechat P, Piette JC: Very low blood hydroxychloroquine concentration as an objective marker of poor adherence to treatment of systemic lupus erythematosus. Ann Rheum Dis 2007, 66:821-824.

6. Houssiau FA, Vasconcelos C, D'Cruz D, Sebastiani GD, de Ramon Garrido E, Danieli MG, Abramovicz D, Blockmans D, Mathieu A, Direskeneli H, Galeazzi M, Gül A, Levy Y, Petera P, Popovic R, Petrovic R, Sinico RA, Cattaneo R, Font J, Depresseux G, Cosyns JP, Cervera R: Immunosuppressive therapy in lupus nephritis: the Euro-Lupus Nephritis Trial, a randomized trial of low-dose versus high-dose intravenous cyclophosphamide. Arthritis Rheum 2002, 46:2121-2131.

7. Houssiau FA, D'Cruz D, Sangle S, Remy P, Vasconcelos C, Petrovic R, Fiehn C, de Ramon Garrido E, Gilboe IM, Tektonidou M, Blockmans D, Ravelingien I, le Guern V, Depresseux G, Guillevin L, Cervera R for the MAINTAIN Nephritis Trial Group: Azathioprine versus mycophenolate mofetil for long-term immunosuppression in lupus nephritis: results from the MAINTAIN Nephritis Trial. Ann Rheum Dis 2010, 69:2083-2089.

8. Condon MB, Griffith MH, Cook HT, Levy JB, Lighstone L and Cairns T: Treatment of Class IV lupus nephritis with rituximab and mycophenolate mofetil (MMF) with no oral steroids is effective and safe. J Am Soc Nephrol 2009, 21:419A.

9. Houssiau FA, Vasconcelos C, D'Cruz D, Sebastiani GD, de Ramon Garrido E, Danieli MG, Abramovicz D, Blockmans D, Mathieu A, Direskeneli H, Galeazzi M, Gül A, Levy Y, Petera P, Popovic R, Petrovic R, Sinico RA, Cattaneo R, Font J, Depresseux G, Cosyns JP, Cervera R: Early response to immunosuppressive therapy predicts good renal outcome in lupus nephritis: lessons from long-term followup of patients in the Euro-Lupus Nephritis Trial. Arthritis Rheum 2004, 50:3934-3940.

10. El Hachmi M, Jadoul M, Lefèbvre C, Depresseux G, Houssiau FA: Relapses of lupus nephritis: incidence, risk factors, serology and impact on outcome. Lupus 2003, 12:692-696.

11. Moroni G, Gallelli B, Quaglini S, Banfi G, Rivolta E, Messa P, Ponticelli C: Withdrawal of therapy in patients with proliferative lupus nephritis: longterm follow-up. Nephrol Dial Transplant 2006, 21:1541-1548.

12. Urowitz MB, Bookman AA, Koehler BE, Gordon DA, Smythe HA, Ogryzlo MA: The bimodal mortality pattern of systemic lupus erythematosus. Am J Med 1976, 60:221-225

13. Roman MJ, Shanker BA, Davis A, Lockshin MD, Sammaritano L, Simantov R Crow MK, Schwartz JE, Paget SA, Devereux RB, Salmon JE: Prevalence and correlates of accelerated atherosclerosis in systemic lupus erythematosus. N Engl J Med 2003, 349:2399-2406.

14. Asanuma Y, Oeser A, Shintani AK, Turner E, Olsen N, Fazio S, Linton MF, Raggi $P$, Stein CM: Premature coronary-artery atherosclerosis in systemic lupus erythematosus. N Engl J Med 2003, 349:2407-2415.

15. Nzeusseu Toukap A, Depresseux G, Devogelaer JP, Houssiau FA: Oral pamidronate prevents high-dose glucocorticoid-induced lumbar spine bone loss in premenopausal connective tissue disease (mainly lupus) patients. Lupus 2005, 14:517-520.

16. Naveau C, Houssiau FA: Pneumococcal sepsis in patients with systemic lupus erythematosus. Lupus 2005, 14:903-906.

17. Tam LS, Chan PK, Ho SC, Yu MM, Yim SF, Cheung TH, Wong MC, Li EK: Natural history of cervical papilloma virus infection in systemic lupus erythematosus - a prospective cohort study. J Rheumatol 2010, 37:330-340.

18. Austin HA 3rd, Klippel JH, Balow JE, le Riche NG, Steinberg AD, Plotz PH, Decker JL: Therapy of lupus nephritis. Controlled trial of prednisone and cytotoxic drugs. N Engl J Med 1986, 314:614-619.

19. Boumpas DT, Austin HA 3rd, Vaughn EM, Klippel JH, Steinberg AD, Yarboro $\mathrm{CH}$, Balow JE: Controlled trial of pulse methylprednisolone versus two regimens of pulse cyclophosphamide in severe lupus nephritis. Lancet 1992, 340:741-745.

20. Gourley MF, Austin HA 3rd, Scott D, Yarboro CH, Vaughan EM, Muir J, Boumpas DT, Klippel JH, Balow JE, Steinberg AD: Methylprednisolone and cyclophosphamide, alone or in combination, in patients with lupus nephritis. A randomized, controlled trial. Ann Intern Med 1996, 125:549-557.

21. Houssiau FA, D'Cruz DP, Haga HJ, Hughes GR: Short course of weekly lowdose intravenous pulse cyclophosphamide in the treatment of lupus nephritis: a preliminary study. Lupus 1991, 1:31-35

22. Chan TM, Li FK, Tang CS, Wong RW, Fang GX, Ji YL, Lau CS, Wong AK, Tong MK, Chan KW, Lai KN: Efficacy of mycophenolate mofetil in patients with diffuse proliferative lupus nephritis. Hong Kong-Guangzhou Nephrology Study Group. N Engl J Med 2000, 343:1156-1162.

23. Sollinger HW: Mycophenolate mofetil for the prevention of acute rejection in primary cadaveric renal allograft recipients. U.S. Renal Transplant Mycophenolate Mofetil Study Group. Transplantation 1995, 60:225-232.

24. Cravedi P, Perna A, Ruggenenti P, Remuzzi G: Mycophenolate mofetil versus azathioprine in organ transplantation. Am J Transplant 2009, 9:2856-2857.

25. Ginzler EM, Dooley MA, Aranow C, Kim MY, Buyon J, Merrill JT, Petri M, Gilkeson GS, Wallace DJ, Weisman MH, Appel GB: Mycophenolate mofetil or intravenous cyclophosphamide for lupus nephritis. N Engl J Med 2005 353:2219-2228.

26. Appel GB, Contreras G, Dooley MA, Ginzler EM, Isenberg D, Jayne D, Li LS, Mysler E, Sanchez-Guerrero J, Solomons N, Wofsy D; Aspreva Lupus Management Study Group: Mycophenolate mofetil versus cyclophosphamide for induction treatment of lupus nephritis. J Am SoC Nephrol 2009, 20:1103-1112.

27. Contreras G, Pardo V, Leclercq B, Lenz O, Tozman E, O'Nan P, Roth D: Sequential therapies for proliferative lupus. N Engl J Med 2004, 350:971-980.

28. Ginzler EM, Appel GB, Dooley MA, Isenberg DA, Jayne D, Wofsy D, Solomons N, Lisk L, Close DR: Aspreva Lupus Management Study (ALMS): maintenance results. Arthritis Rheum 2010, 62 (suppl):S879.

29. Stoenoiu MS, Aydin S, Tektonidou M, Ravelingien I, le Guern V, Fiehn C, Remy P, Delahousse M, Petera P, Quémeneur T, Vasconcelos C, D'Cruz D, Gilboe IM, Jadoul M, Karras A, Depresseux G, Guillevin L, Cervera R, Cosyns JP, Houssiau FA; for the MAINTAIN Nephritis Trial Group: Repeat kidney biopsies fail to detect differences between azathioprine and mycophenolate mofetil maintenance therapy for lupus nephritis: data from the MAINTAIN Nephritis Trial. Nephrol Dial Transplant 2011 Nov 22. [Epub ahead of print]

30. Rovin BH, Furie R, Latinis K, Looney RJ, Fervenza FC, Sanchez-Guerrero J, Maciuca R, Zhang D, Garg JP, Brunetta P, Appel G; for the LUNAR Investigator Group: Efficacy and safety of rituximab in patients with active proliferative lupus nephritis: The lupus nephritis assessment with rituximab (LUNAR) study. Arthritis Rheum 2012, doi: 10.1002/art.34359. [Epub ahead of print].

31. Spindler AJ, Guzman R, Bijl M, Jayne D, Furie RA, Maciuca R, Shahdad S, Close D, Brunetta P, Drappa J: Efficacy and safety of ocrelizumab, a humanized antiCD20 antibody, in patients with active proliferative lupus nephritis (LN): results from the randomized, double-blind phase III BELONG study. Arthritis Rheum 2010, 62 (suppl):S606.

32. Merrill JT, Neuwelt CM, Wallace DJ, Shanahan JC, Latinis KM, Oates JC, Utset TO, Gordon C, Isenberg DA, Hsieh HJ, Zhang D, Brunetta PG: Efficacy and safety of rituximab in moderately-to-severely active systemic lupus erythematosus: the randomized, double-blind, phase II/III systemic lupus erythematosus evaluation of rituximab trial. Arthritis Rheum 2010, $62 \cdot 222-233$

33. Lu TY, Ng KP, Cambridge G, Leandro MJ, Edwards JC, Ehrenstein M, Isenberg $D A$ : A retrospective seven-year analysis of the use of $B$ cell depletion therapy in systemic lupus erythematosus at University College London Hospital: the first fifty patients. Arthritis Rheum 2009, 61:482-487.

34. Wallace DJ, Kalunian KC, Petri MA, Strand V, Kilgallen B, Kelley L, Gordon CP Epratuzumab demonstrates clinically meaningful improvements in patients with moderate to severe systemic lupus erythematosus (SLE): 
results from EMBLEM"' ${ }^{\text {TM }}$, a phase llb study. Arthritis Rheum 2010, 62 (suppl):S605.

35. Furie R, Nicholls K, Cheng TT, Houssiau F, Burgos-Vargas R, Chen SL, et al:: Efficacy and safety of abatacept over 12 months in patients with lupus nephritis: results from a multicenter, randomized, double-blind, placebocontrolled phase II/III study [abstract]. Arthritis Rheum 2011, 63(Suppl 10):2469.

36. Navarra SV, Guzman RM, Gallacher AE, Hall S, Levy RA, Jimenez RE, Li EK, Thomas M, Kim HY, Leon MG, Tanasescu C, Nasonov E, Lan JL, Pineda L, Zhong ZJ, Freimuth W, Petri MA; BLISS-52 Study Group: Efficacy and safety of belimumab in patients with active systemic lupus erythematosus: a randomised, placebo-controlled, phase 3 trial. Lancet 2011, 377:721-731.

37. Furie R, Petri M, Zamani O, Cervera R, Wallace DJ, Tegzová D, SanchezGuerrero J, Schwarting A, Merrill JT, Chatham WW, Stohl W, Ginzler EM, Hough DR, Zhong ZJ, Freimuth W, van Vollenhoven RF; BLISS-76 Study Group: A phase III, randomized, placebo-controlled study of belimumab, a monoclonal antibody that inhibits B lymphocyte stimulator, in patients with systemic lupus erythematosus. Arthritis Rheum 2011, 63:3918-3930.
38. Austin HA 3rd, Illei GG, Braun MJ, Balow JE: Randomized, controlled trial of prednisone, cyclophosphamide, and cyclosporine in lupus membranous nephropathy. J Am Soc Nephrol 2009, 20:901-911.

39. Radhakrishnan J, Moutzouris DA, Ginzler EM, Solomons N, Siempos II, Appel GB: Mycophenolate mofetil and intravenous cyclophosphamide are similar as induction therapy for class V lupus nephritis. Kidney Int 2010 77:152-160.

doi:10.1186/ar3656

Cite this article as: Houssiau FA: Therapy of lupus nephritis: lessons learned from clinical research and daily care of patients. Arthritis Research \& Therapy 2012, 14:202 